University of the Pacific

Scholarly Commons

All Faculty Articles - School of Engineering and Computer Science

All Faculty Scholarship

$11-1-2014$

\title{
Design Studies of Swept Wind Turbine Blades
}

Scott M. Larwood

University of the Pacific, slarwood@pacific.edu

C. P. Van Dam

University of California, Davis

Daniel Schow

University of California, Davis

Follow this and additional works at: https://scholarlycommons.pacific.edu/soecs-facarticles

Part of the Engineering Commons

\section{Recommended Citation}

Larwood, S. M., Van Dam, C. P., \& Schow, D. (2014). Design Studies of Swept Wind Turbine Blades.

Renewable Energy, 71, 563-571. DOI: 10.1016/j.renene.2014.05.050

https://scholarlycommons.pacific.edu/soecs-facarticles/3

This Article is brought to you for free and open access by the All Faculty Scholarship at Scholarly Commons. It has been accepted for inclusion in All Faculty Articles - School of Engineering and Computer Science by an authorized administrator of Scholarly Commons. For more information, please contact mgibney@pacific.edu. 


\title{
Design Studies of Swept Wind Turbine Blades
}

\author{
Scott Larwood ${ }^{\mathrm{a}}$, C. P. van Dam ${ }^{\mathrm{b}}$, Daniel Schow ${ }^{\mathrm{c}, \mathrm{d}}$ \\ ${ }^{a}$ Mechanical Engineering Dept.,University of the Pacific, 3601 Pacific Ave., Stockton, \\ CA 95203 \\ ${ }^{b}$ Dept. of Mechanical and Aerospace Engineering, UC Davis, One Shields Ave., Davis, \\ CA 95616 \\ ${ }^{c}$ Mechanical Engineering Dept.,University of the Pacific, 3601 Pacific Ave., Stockton, \\ CA 95203 \\ ${ }^{d}$ current address: Royce Instruments, 831 Latour Ct., Napa, CA 94558
}

\begin{abstract}
The growth of wind energy is sustained by innovation that lowers the cost of energy. One recent innovation is the swept blade, which deflects in operation and lowers loads. With sweep, a design rotor diameter can increase, capturing more power, with the loads remaining within limits. This concept has been demonstrated in a U.S. program and is in commercial production. This paper describes a parametric study of swept blade design parameters for a $750 \mathrm{~kW}$ machine. The amount of tip sweep had the largest effect on the energy production and blade loads; other parameters had less impact. The authors then conducted a design study to implement a swept design on 1.5 MW, $3 \mathrm{MW}$, and $5 \mathrm{MW}$ turbines. An aeroelastic code, previously described, was developed to model the behavior and determine the loads of the swept blade. The design goal was to increase annual energy production 5\% over the straight blade, without increasing blade loads. Successful designs were developed for the 1.5 MW and 3.0 MW turbines. The swept $5 \mathrm{MW}$ turbine exhibited a twist instability at high wind speeds. Further study is required
\end{abstract}


to determine if sweep can be implemented for larger turbines, which are approaching flutter boundaries in unswept designs.

Keywords:

Wind energy, rotor blades, sweep, passive load control 
1

2

3

4

5

6

7

8

\section{Background}

\subsection{Introduction}

Given the static policy environment, lowering the cost of energy (COE) is the primary means for continued growth of the wind energy industry. One method for lowering the COE is to increase the rotor diameter to capture more power; however, the loads on the blades and turbine increase. Turbine components must be strengthened to withstand the increased loads, raising costs. There are several methods to lower the loads on blades, and they fall into two categories: active and passive load control.

Active load controls implies that energy (actuation) be provided to control load. Active methods include individual pitch control [1], and active aerodynamic control [2] [3]. The disadvantages with active control are added complexity, potential reliability problems, and added power requirements.

Passive load control implies that the system acts in a manner which reduces loads when disturbed. Two examples are bend-twist coupling [4] and blade sweep. With all methods, the rotor diameter can be increased given the same load envelope as a baseline design.

A swept blade is more complex to manufacture and increases cost; however, the cost of energy overall is lowered because more power is produced. The loads are reduced because in turbulent winds the blade tip twists and lowers the aerodynamic forces (passive load control). Figure 1 illustrates the concept, with the tip of the loaded blade (dashed line) twisting counterclockwise, lowering its angle of attack which lowers the aerodynamic forces.

Liebst [5] and Zuteck [6] proposed using swept blades on wind turbines for passive load control. Liebst analyzed a model of a $10 \mathrm{~kW}$ turbine with swept 


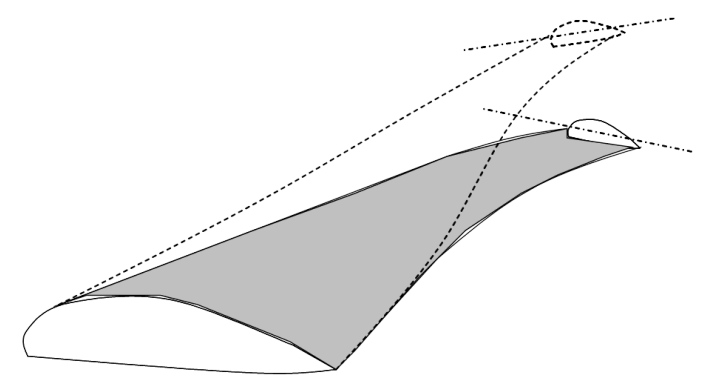

Figure 1: Swept blade concept: solid line represents unloaded, dashed line represents loaded with tip twisting

blades. His objective was to lower the loads for a given rotor diameter. The analysis showed that lowering the torsional rigidity (flexibility in twist) of the blade would be necessary for effective load relief. Zuteck proposed sweep as an alternative to bend-twist coupling, and conducted design studies with sweep on a $1 \mathrm{MW}$ wind turbine. He also found that lowering the torsional stiffness would be necessary to obtain sufficient twisting; on the order of $5^{\circ}$. He also proposed increasing the rotor diameter to lower the cost of energy. As a follow-on to Zuteck's work, a team led by Knight \& Carver produced the STAR (swept-twist adaptive rotor) [7] for a U.S. Department of Energy program. The STAR program included the design and manufacture of a swept blade rotor with increased diameter for a $750 \mathrm{~kW}$ turbine. Two blades were constructed for laboratory tests, and a complete rotor set was installed on a Zond Z-48 turbine in Tehachapi, California, as shown in Fig. 2. The STAR turbine showed a $12 \%$ increase in energy capture over similar turbines in the wind plant. The measured loads on the STAR turbine were below the design loads for the Z-48 turbines, and were similar to loads measured on Z-48 turbines at other wind plants. 


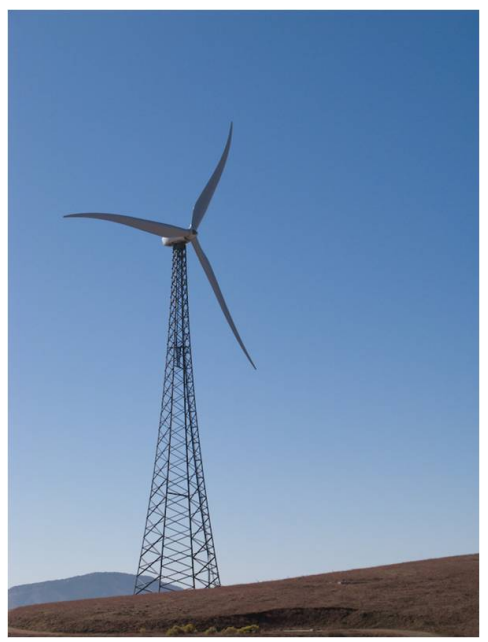

Figure 2: STAR swept blade rotor in Tehachapi, CA 2008 (photo by H. Shiu)

43 Verelst and Larsen [8] described parametric modeling of swept blades on 44 a 5 MW turbine with 120 variations in the sweep parameters. Their study included forward sweep of the blades. They found load benefits in backward swept blades but instabilities in forward swept blades. Siemens started large scale production on $53 \mathrm{~m}$ swept blades (with the name Aeroelastic Tailored Blade) for a 3 MW turbine in 2012.

49 this work, the authors performed a parametric study of swept blade design parameters for the STAR blade. The results show that amount of tip sweep is the most sensitive parameter for load reduction. The authors used this information to design swept blades for 1.5 MW, 3.0 MW and 5.0 MW wind turbines. The design goal was to increase annual energy production (AEP) by $5 \%$ over a baseline straight blade and lower the lifetime flapwise bending loads (Fig. 1 shows the blade in flapwise bending). The 1.5 MW and $3 \mathrm{MW}$ designs show successful increase in AEP and lowering of flap bending loads. 
58 The swept 5 MW turbine exhibited a twist instability at high wind speeds.

59 Further study is required to determine if sweep can be implemented for larger

60 turbines, which are approaching flutter boundaries in unswept designs. 


\section{Methods}

Figure 3 shows the blade sweep parameters for this analysis. The sweep curve starts a specified distance along a blade, at about $40 \%$ of the radius for the STAR blade [7]. The authors expected that sweeping the entire blade increases manufacuturing complexity with no benefit. The tip sweep is the distance from the pitch axis of the blade (about which the entire blade rotates while being pitched) to the sweep curve. The sweep curve as established by Zuteck in the STAR program was:

$$
y=d_{\text {tip }}\left(\frac{x-x_{\text {start }}}{L_{\text {blade }}-x_{\text {start }}}\right)^{\gamma}
$$

where $y$ is the local distance from the pitch axis to the sweep curve, $d_{t i p}$ is the distance from the pitch axis to the sweep curve at the blade tip, $x$ is the local distance along the blade measured from the blade root, $x_{\text {start }}$ is the position of the beginning of the blade sleep, $L_{\text {blade }}$ is the length of the blade, and $\gamma$ is the sweep exponent. Another design parameter is the torsional stiffness, which is a measure of the twisting flexibility of the blade about the elastic axis.

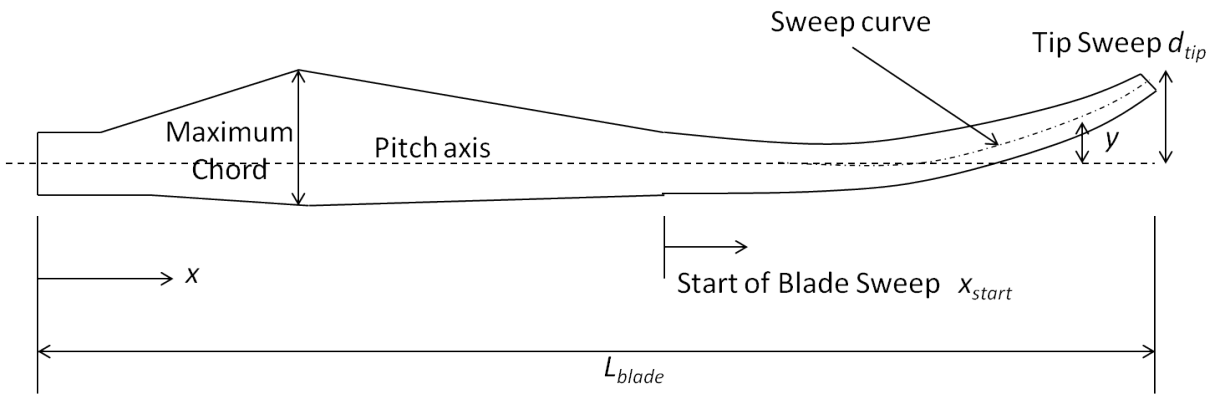

Figure 3: Swept blade parameters 
For the swept blade analysis, the authors used CurveFAST, which is an extension of the National Renewable Energy Laboratory's (NREL) FAST [10] wind turbine analysis code. CurveFAST models the swept blade motions and aerodynamics (aeroelastic modeling) under turbulent wind conditions.

The blade model allows for four mode shapes, which are are the blade shapes when vibrating at the particular mode's natural frequency. Figure 1 is an example of the first mode shape, which is mostly flap bending in addition to twisting. The three other mode shapes are called first edge bending, second flap bending, and first torsion. Edge bending is mostly in-plane motion, tranverse to that shown in Fig. 1. The mode shapes are determined by a finite element code called CurveFEM, which models the blade under rotation. These mode shapes are then input to CurveFAST.

Larwood and van Dam [11] report on verification and validation of CurveFAST. 'Verification' is defined as comparison with results from other software programs/solutions (are the equations solved correctly), and 'validation' is defined as comparison to test data (are the correct equations being used). The verification used the multi-body code Adams ${ }^{\mathrm{TM}}$ and showed agreement to within $5 \%$ on power, flap bending, and edge bending loads. Validation with field test results were inconclusive due to uncertainties in the wind speed measurements and the turbine controller.

The current design study includes modeling that is similar to the normal turbulence model (NTM) for the IEC (International Electrotechnical Commission) 61400-1 Design Requirements for Wind Turbines [12]. Each model run was a 10-minute turbulent simulation, which had a nominal 10 minute average wind speed varying from $3 \mathrm{~m} / \mathrm{s}$ to $25 \mathrm{~m} / \mathrm{s}$ in $2 \mathrm{~m} / \mathrm{s}$ steps. The NREL 
program TurbSim [13 generated the wind files with the Kaimal spectrum for the IECA normal turbulence model. Each wind speed step consisted of five ten-minute simulations with the random seed equal to the computer system clock. The random seed insures that each wind file will have a different times series but same average wind speed and turbulence intensity (wind speed standard deviation over average). Each model therefore had 60 runs (12 steps with 5 runs each).

The annual energy production was then compared amongst models. The average power produced at each wind speed step (e.g. $7 \mathrm{~m} / \mathrm{s}$ ) is multiplied by the number of hours per year at the particular wind speed. The hours per year are determined from the Rayleigh probability distribution:

$$
F(V)=1-\exp \left(-\frac{\pi}{4}\left(\frac{V}{V_{\text {ave }}}\right)^{2}\right),
$$

where $F(V)$ is the frequency that the velocity $V$ or lower will occur, and $V_{\text {ave }}$ is the average wind speed of the distribution. An annual average wind speed of $8.5 \mathrm{~m} / \mathrm{s}$ was used, which corresponds to IEC class II. From the lead author's experience in the industry, most of the wind turbine sales in the U.S. are for this class. The number of hours per year at wind speed $V_{i}$ is from:

$$
\text { Hours at wind speed } V_{i}=8760\left(F\left(V_{i}\right)-F\left(V_{i-1}\right)\right) \text {, }
$$

with the calculation initiated at:

$$
V_{i-1}=V_{i}-1 \mathrm{~m} / \mathrm{s}
$$

The total sum of these kilowatt-hours is the annual energy production. Figure 4 shows the Rayleigh distribution for and $8.5 \mathrm{~m} / \mathrm{s}$ average wind speed along with the power curve for $1.5 \mathrm{MW}$ wind turbine. 


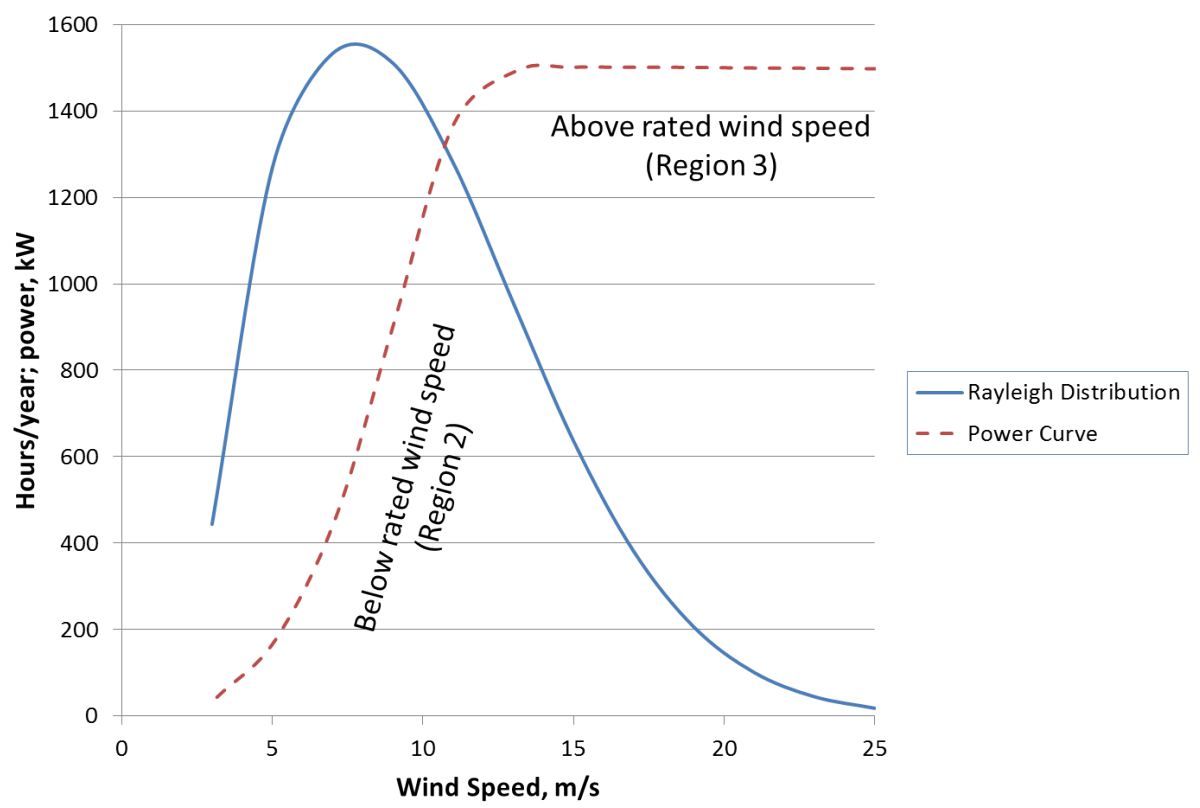

Figure 4: Rayleigh wind speed distribution along with power curve for 1.5 MW wind turbine, showing below rated wind speed (Region 2) and above rated wind speed (Region

3)

The loads were also compared amongst models. More specifically, the comparison is between the damage equivalent loads (DEL). The damage equivalent load is a single number that represent a lifetime of turbine loads. A turbine withstands about 100 million load cycles of various amplitudes during its lifetime. Figure 5 shows an example 10-minute time series of the blade root bending moment in the flap direction. The figure shows several load levels at various frequencies.

The DEL represents a lifetime of these loads levels and frequencies as a single number for a particular number of cycles; one-million for the current study. Freebury and Musial [14] and Sutherland [15] discuss this method. 


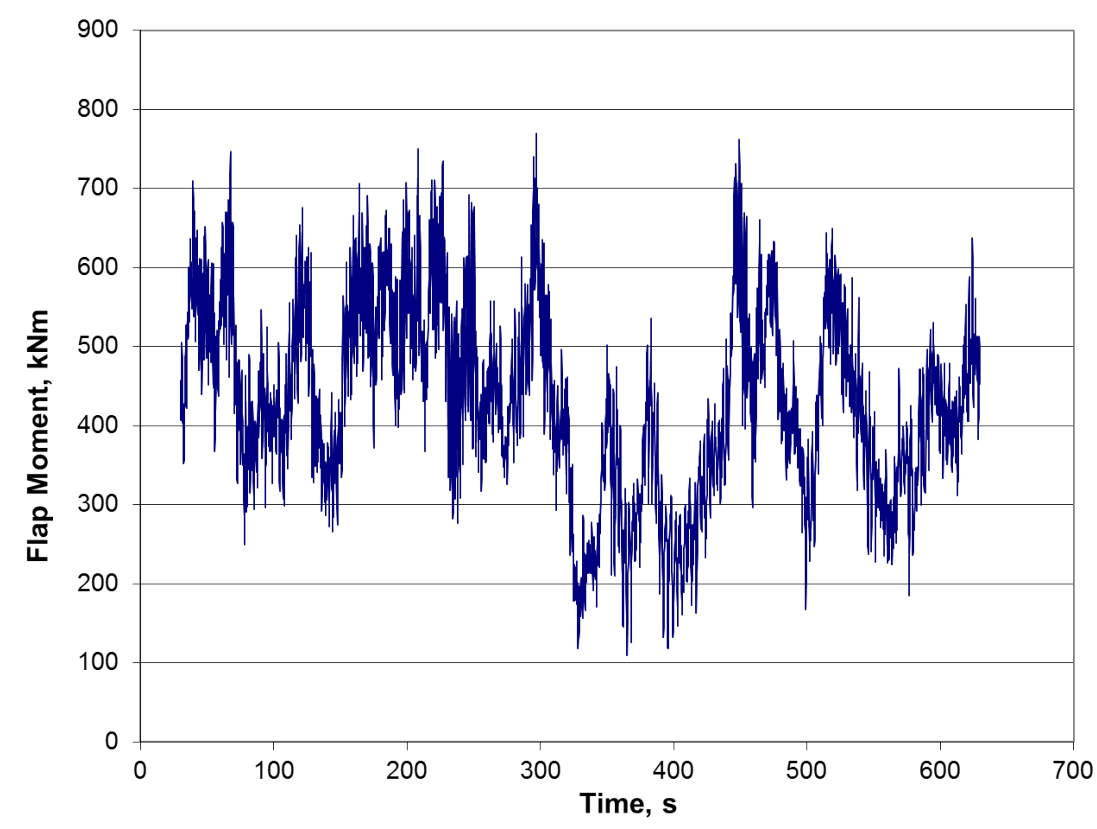

Figure 5: Blade root flap bending for a $750 \mathrm{~kW}$ wind turbine

Details of the calculation are included in the Appendix Section Appendix A.

\subsection{Parametric study}

The purpose of the parametric study was to determine the impact of the sweep parameters on the energy production and loads. This study later informed the decisions made in the scaling study (Sec. 2.2). The study was performed using the STAR7d model, which was the final design of the STAR program [7], and was used to verify CurveFAST [11]. Section torsional stifness, the sweep exponent, and the tip sweep were varied. Higher sweep exponents place more curvature outboard, as shown in Fig. 6. Manufacturing is affected by the shape of the sweep curve because the construction materials, primarily woven fiberglass sheets, have limits to their curvature. Tip sweep 

tip sweep was limited to the envelope of maximum chord.

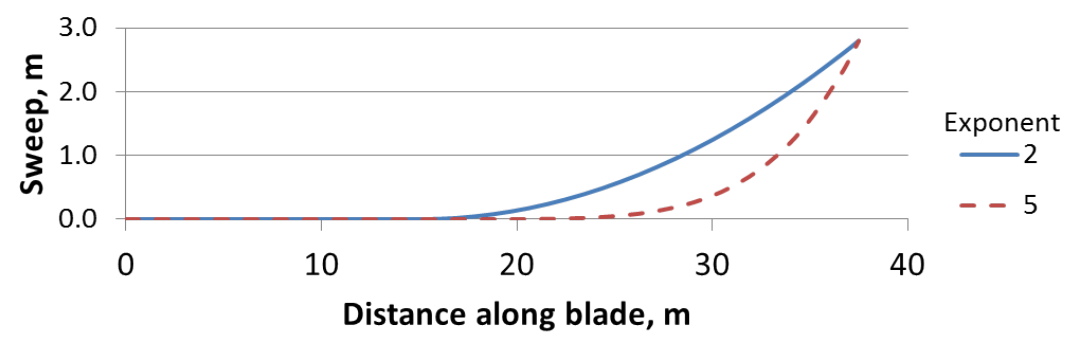

Figure 6: Sweep for a 1.5 MW turbine with two different exponents (note $y$-axis scale does not match $x$-axis scale

is affected by transportation requirements, and for the STAR program the

(1) match $x$-axis scale

The STAR program team conducted a cursory design study by changing the sweep parameters individually for an individual load case at rated wind speed. For the current study, a more thorough investigation was performed to study the impact on the sweep parameters. The impact on both the loads and annual energy production was determined. Table 1 shows the parameters that were varied and by what amount. Each parameter change was a complete model of 60 runs as mentioned above.

In addition to determining the annual energy production and damage equivalent load, the peak blade tip deflection was determined from the model runs.

To determine the statistical distribution of the runs, the baseline model was run for five sets of sixty runs. Between the five runs, the standard deviations of the outputs were: annual energy production $0.24 \%$, flap-bending damage equivalent load 2.1\%, edge-bending damage equivalent load $0.17 \%$, and maximum tip deflection $1.69 \%$. 
Table 1: Parametric Study

\begin{tabular}{|c|c|}
\hline Parameter & Percentage from Baseline \\
\hline Torsional Stiffness & $+20 \%$ \\
\hline Torsional Stiffness & $-20 \%$ \\
\hline Sweep Exponent & $+20 \%$ \\
\hline Sweep Exponent & $-20 \%$ \\
\hline Tip Sweep & $+15 \%$ \\
\hline Tip Sweep & $-15 \%$ \\
\hline
\end{tabular}

\subsection{Scaling study}

For the scaling study, baseline models of $1.5 \mathrm{MW}, 3.0 \mathrm{MW}$ and 5.0 MW rating were used. The $1.5 \mathrm{MW}$ and 3.0 MW models originated from the WindPACT study [16]. The 1.5 MW is included in the FAST code distribution [10]. Craig Hansen, who was involved in the WindPACT study, provided the 3.0 MW model data. The 5.0 MW model is described in an NREL report [17]. Other researchers use this model, such as Verelst [8]; however Verelst did not expand the rotor diameter.

The baseline models were run in the same manner as the parametric study to obtain annual energy production and damage equivalent loads. Table 2 shows various model parameters.

Blade properties for the 1.5 MW and $3 \mathrm{MW}$ models are included in Appendix B. These properties were interpolated from six to twenty blade analysis stations. Blade properties for the $5 \mathrm{MW}$ model are included in the NREL report [17]. 
Table 2: Scaling Study Model wind parameters

\begin{tabular}{|l|c|c|c|}
\hline Model & WP1500 & WP3000 & NREL 5 MW \\
\hline Rated power, kW & 1500 & 3000 & 5000 \\
\hline Radius, m & 35.5 & 49.5 & 63 \\
\hline Maximum chord, m & 2.80 & 3.96 & 4.65 \\
\hline Rated generator speed, rpm & 1800 & 1800 & 1174 \\
\hline Rated rotor speed, rpm & 20.463 & 14.469 & 12.100 \\
\hline Hub radius, m & 1.65 & 2.325 & 1.50 \\
\hline Hub height, m & 84 & 119 & 90 \\
\hline Gearbox efficiency, \% & 100 & 100 & 100 \\
\hline Generator efficiency, \% & 95 & 95 & 94.4 \\
\hline Gearbox ratio & 87.965 & 124.4 & 97.0 \\
\hline
\end{tabular}


The baseline turbines were scaled for swept blades by increasing the rotor swept area by $25 \%$ percent. This was the method employed in the STAR program to obtain an approximate 5\% increase in annual energy production of the the baseline straight-blade turbine. The new model's maximum chord was the same as the baseline, which was at the $25 \%$ radial position. To optimize the new blade planform, the Betz method (outlined in Gasch and Twele [18]) was used. For this method, the baseline optimal tip speed ratio was scaled by the ratio of the new swept rotor radius to the baseline rotor radius. The tip speed ratio $\lambda$ is determined by:

$$
\lambda=\frac{V_{t i p}}{U_{\infty}}
$$

where $V_{t i p}$ is the velocity of the blade tip and $U_{\infty}$ is the wind speed. Below the rated wind speed of the turbine (variable speed region), there exists an optimal blade pitch setting and tip speed ratio that provides maximum aerodynamic efficiency (maximum power coefficient). The optimal tip speed ratio was 7.0 for the WP1500 and WP3000 models; and 7.55 for NREL 5 MW.

The swept blade used the maximum chord of the baseline blade at $25 \%$ radial station, and the Betz-optimized chord at the $75 \%$ radial station. The chord distribution was linearly tapered from these two positions, with the tip chord not falling below $300 \mathrm{~mm}$ as a manufacturing constraint. The Betz method provides a non-linear chord distribution, but designers use linear distribution to ease manuafacturing with minimal loss in performance. The twist distribution was from the Betz-optimized twist distribution based on the maximum lift over drag value (L/D) and corresponding angle of attack for the $75 \%$ radial position section shape. The maximum twist was 11.1 
degrees, which was the WindPACT value. This maximum occurs around the maximum chord; inboard the airfoils transition to a round root section.

The swept blade's stiffness properties were the same as the baseline at the same blade station normalized by the blade length. This was approximately the same situation with the STAR7d and its baseline straight blade. The only exception was the torsional stiffness, which was varied in the design process. The blade lineal density $(\mathrm{kg} / \mathrm{m})$ was adjusted by a common factor so that the static moment (moment of the blade about the root due to gravity) was the same for the baseline and the extended blade. The STAR designers were able to accomplish this matching of the blade static moments.

Simulations of the new rotors were run with the WT_Perf performance code [19] to determine control settings for the variable speed region. The settings are pitch setting and tip speed ratio that result in the maximum aerodynamic efficiency (maximum power coefficient). For the pitch control above rated, the WindPACT pitch control model was used to run simulations with stepped wind speeds above rated. The controller was tuned by adjusting the proportional gain to ensure stable behavior to stepped wind inputs.

Normal turbulence model simulations were run as for the baseline machines, with annual energy production and damage equivalent loads computed in post-processing. The results were compared to the baseline case. The sweep parameters were then adjusted to obtain a 5\% AEP increase without increasing the flap bending damage equivalent loads above the baseline. 


\section{Results}

\subsection{Parametric study}

Figures 7, 8 and 9 show the variation in loads, energy production, and maximum blade deflection respectively for the STAR7d parametric study (Table 1). The flap-bending damage equivalent load results (Fig. 7) show tip sweep having the largest effect on the load, with higher tip sweep lowering the load. The sweep exponent and torsional stiffness have less effect on the load.

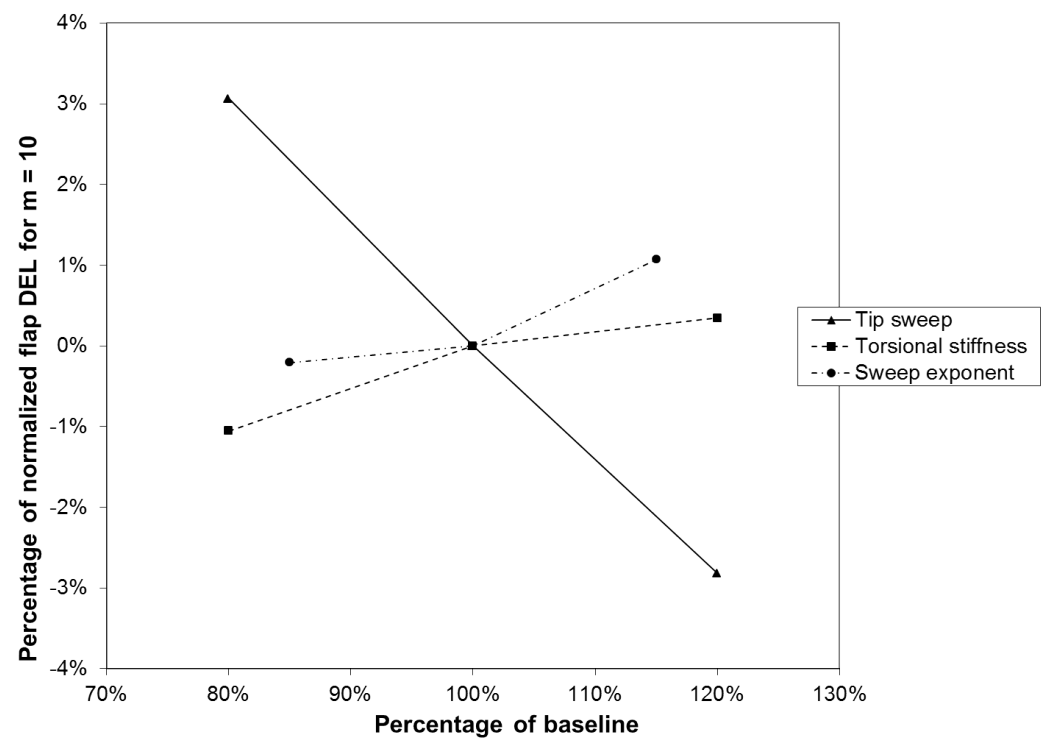

Figure 7: Effect of changing tip sweep, torsional stiffness, and sweep exponent on STAR7d flap bending damage equivalent load $(\mathrm{m}=10)$ straight). 


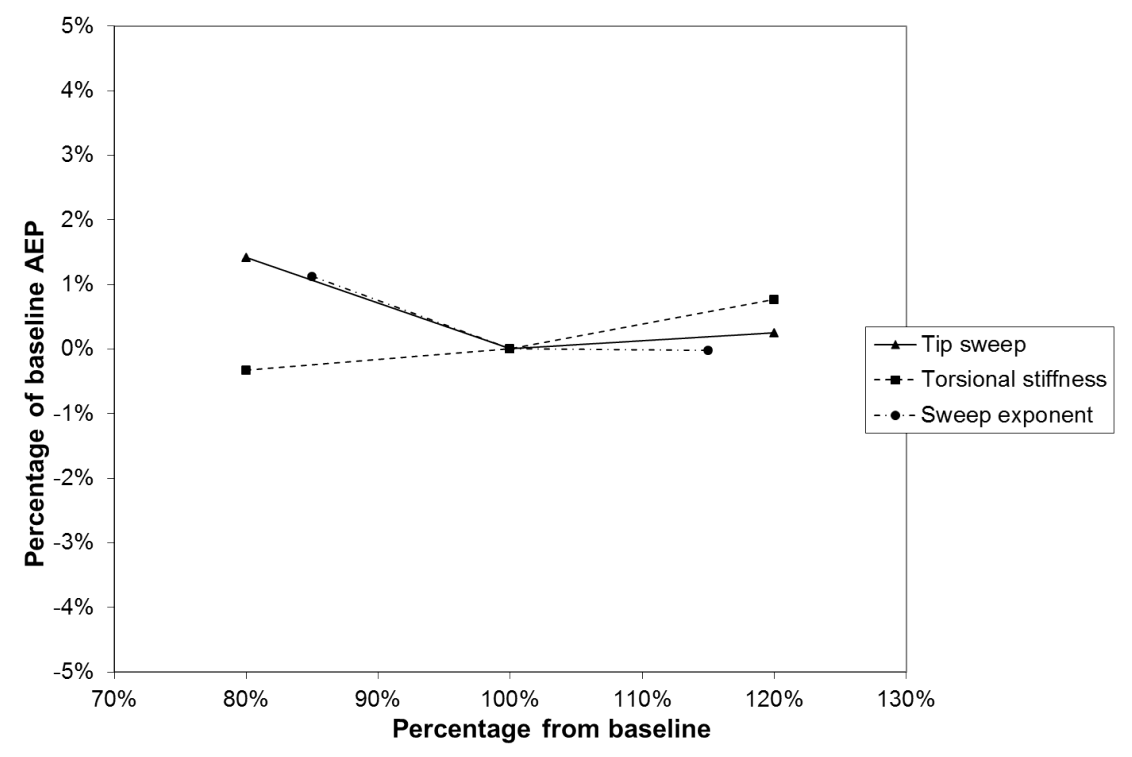

Figure 8: Effect of changing tip sweep, torsional stiffness, and sweep exponent on STAR7d annual energy production

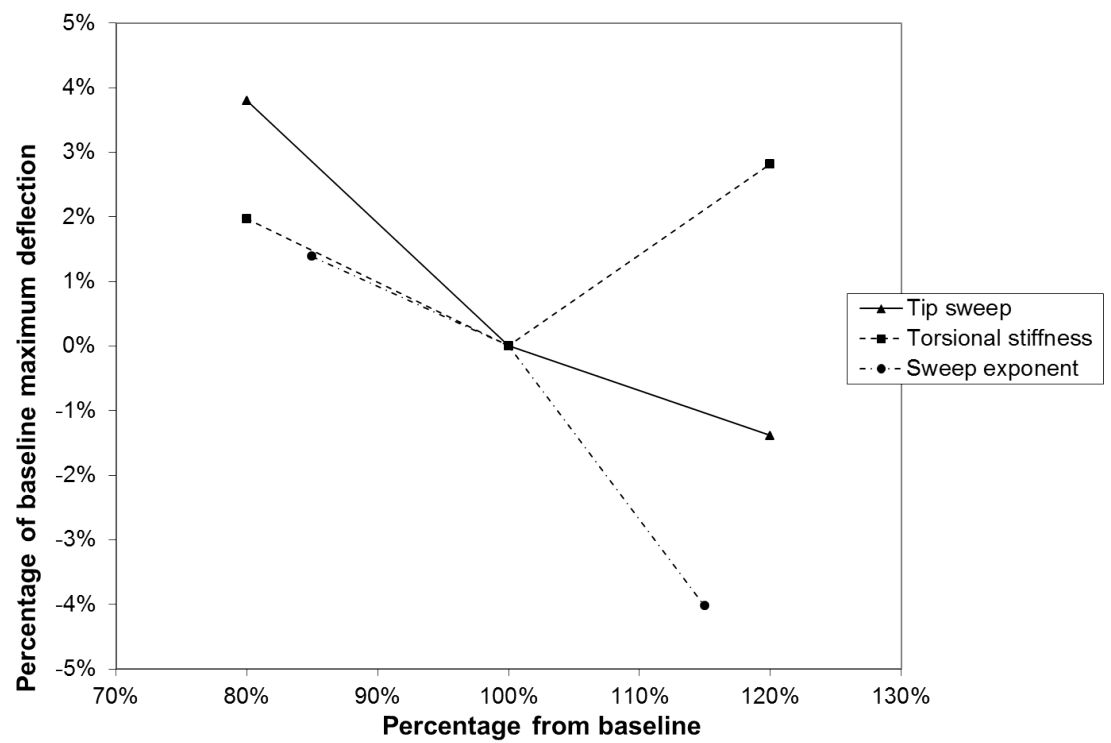

Figure 9: Effect of changing tip sweep, torsional stiffness, and sweep exponent on STAR7d maximum blade tip deflection 
The tip deflection results (Fig. 9) show a decrease in maximum blade deflection with increasing tip sweep and sweep exponent. The results for torsional stiffness are not conclusive.

\subsection{Scaling study}

Table 3 lists the resulting designs, performance, and loads for the three scaled rotor models, Curve1500, Curve3000, and Curve5000. The scaled Curve5000 displayed a twist instability while above rated wind speed, with even a minimal amount of tip sweep (1/4 of maximum chord). An example of the instability is shown in Fig. 10. A straight version of the Curve5000 did not display the instability. The table shows that the energy production has increased $5 \%$ or higher for Curve1500 and Curve3000, with a decrease in the flap-bending damage equivalent load. Compared to the Curve1500, the larger Curve3000 required less tip sweep and no reduction in torsional stiffness to achieve the design goal. The Curve1500 and Curve3000 show an increase in edge-bending damage equivalent load.

Figure 11 below shows the flap damage equivalent load versus 10-minute average wind speed for the $1.5 \mathrm{MW}$ baseline and swept designs. The damage equivalent load is normalized at an arbitrary value slightly above the maximum value. The results show that the loads are similar below rated wind speed (region 2) with the loads for the swept rotor below the straight baseline rotor above rated wind speed (region 3). The $3 \mathrm{MW}$ model showed similar results. 
Table 3: Scaled model results. Twist in Curve5000 with sweep was unstable above rated wind speed.

\begin{tabular}{|l|c|c|c|}
\hline Model & Curve1500 & Curve3000 & Curve5000 \\
\hline Baseline radius, m & 35.5 & 49.5 & 63.0 \\
\hline Stretched radius, m & 39.15 & 55.35 & 70.44 \\
\hline Maximum chord, m & 2.8 & 3.96 & 4.652 \\
\hline Tip sweep, m & 2.8 & 2.376 & - \\
\hline GJ modification & $74 \%$ lower & same as baseline & - \\
\hline Percent AEP over baseline & $6.0 \%$ & $5.5 \%$ & - \\
\hline $\begin{array}{l}\text { Percent Flap DEL under } \\
\text { baseline (m = 10) }\end{array}$ & $15.0 \%$ & $5.8 \%$ & - \\
\hline $\begin{array}{l}\text { Percent Edge DEL over } \\
\text { baseline (m = 10) }\end{array}$ & $1.0 \%$ & $1.8 \%$ & - \\
\hline
\end{tabular}




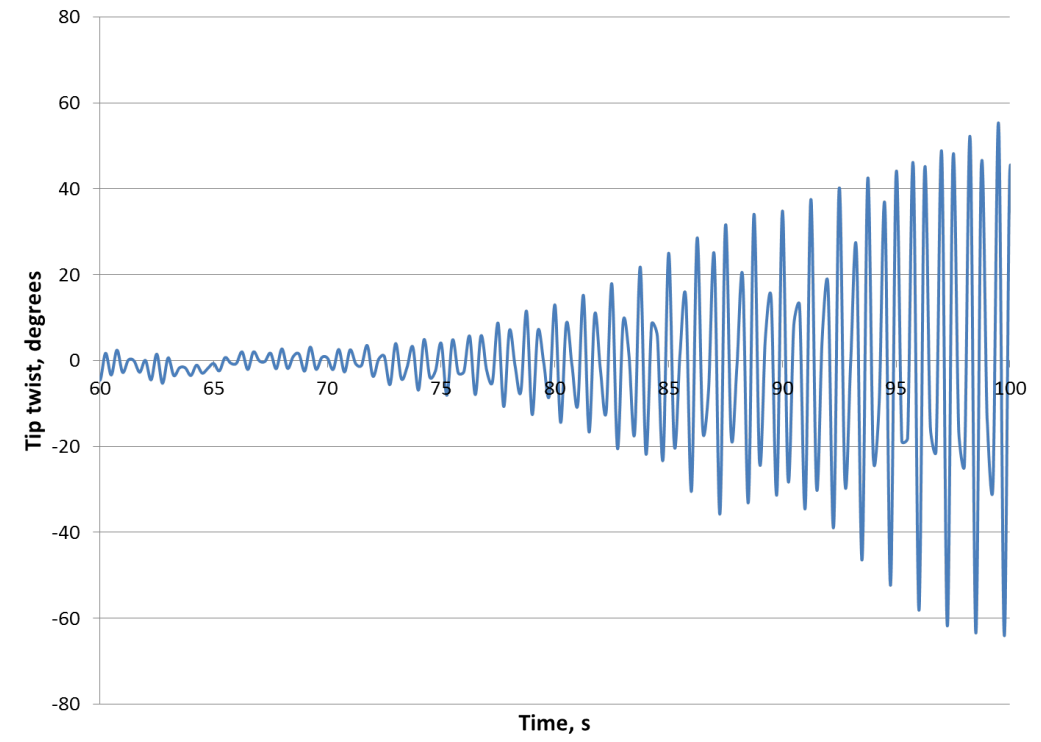

Figure 10: Blade twist instability in swept $5 \mathrm{MW}$ model. The input wind is turbulent 25 $\mathrm{m} / \mathrm{s}$ average.

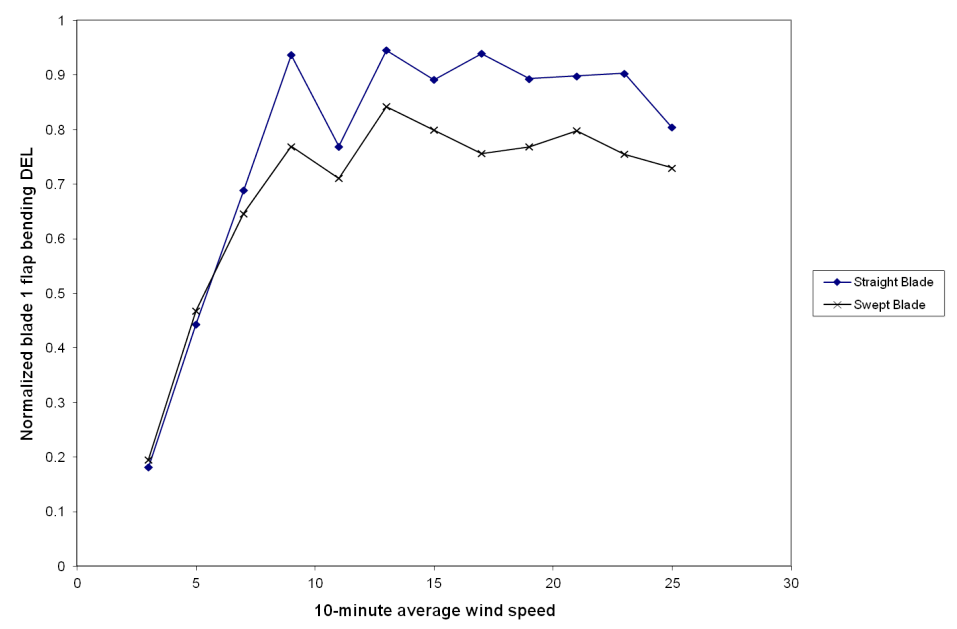

Figure 11: Flap bending damage equivalent load (normalized) versus 10-minute average wind speed for 1.5 MW models 


\section{Discussion}

\subsection{Parametric Study}

The parametric study showed that the loads and energy production were most sensitive to the amount of tip sweep. The sweep curve exponent and torsional stiffness showed less impact on the loads and energy production. Both Liebst [5] and Zuteck [6] discuss the importance of lowering the torsional stiffness to achieve load relief; however, the present study shows that torsional stiffness has less impact.

Higher tip sweep reduces both fatigue loads (Fig. 7) and tip deflection (Fig. 9p). For future study, the IEC extreme load cases in addition to the turbulent operating cases should be analyzed to study changes in maximum blade deflection with tip sweep.

Modifying the sweep curve exponent has less impact on loads. Note that the sweep remains in the outboard blade portion, which Zuteck [6] notes as important. He shows that a circular curve extending inward to the root is less effective than more outboard curvature.

For all of parameters, the change in annual energy production is less than $1 \%$ (Fig. 8). This value is less than the expected accuracy for power performance tests. Therefore, changing the parameters within the range of this study would probably have no noticeable effect on the annual energy production.

\subsection{Scaling Study}

Conceptual designs of swept rotors for 1.5 MW and $3 \mathrm{MW}$ wind turbines were developed. The designs increase energy capture by at least $5 \%$ with an 
increased diameter. With the passive load relief of sweep the flap-bending fatigue loads are decreased over the baseline straight rotor. Edge bending fatigue is increased slightly. The 1.5 MW design required a tip sweep the same as the maximum chord and a $75 \%$ reduction of torsional stiffness. The 3 MW design required less tip sweep relative to the maximum chord and with no change in torsional stiffness required.

The rotor design for the swept $5 \mathrm{MW}$ rotor showed a twist instability at high wind speeds for even minimal tip sweep. This behavior indicates that the straight blade is near the flutter boundary. Flutter stability is governed by the torsional stiffness and the location of the mass center relative to the elastic axis. Sweep places the mass center aft, which increases the susceptability to flutter. Torsional stiffness could be increased to decrease the susceptability to flutter, but this might mitigate the benefits of sweep. Further investigation is required to determine if sweep can be implemented in larger turbines. Both Hansen [20] and Lobitz [21] discuss the problem with flutter and larger turbines.

\subsection{Recommendations for Future Work}

Given the successful operation of the STAR test turbine, and the commercialization of a $3 \mathrm{MW}$ swept rotor, the authors recommend that this concept should be explored further. The following actions are recommended:

1. Determine flutter boundary for $5+\mathrm{MW}$ unswept and swept turbine rotors. Determine if the boundary can be increased and still maintain benefits of sweep,

2. Detailed design studies to expand on the conceptual design with detailed section properties and the full IEC [12] load cases, 
3. Control scheme for region 2 (variable speed) to maximize energy capture that takes into account the active twisting of the blade, 4. Further validation of the swept concept with field tests. 


\section{Acknowledgments}

308 The authors thank the Energy Innovations Small Grant (EISG) Program 309 of the California Energy Commission (CEC) for its financial support for 310 portions of this work under grant number 54905A/06-16. 


\section{Appendix A. Damage Equivalent Load Calculation}

The calculation of the damage equivalent load involves the use of Miner's rule, which is:

$$
\frac{n_{1}}{N_{1}}+\frac{n_{2}}{N_{2}}+\cdots+\frac{n_{n}}{N_{n}}=\text { Damage Fraction }
$$

where $n$-is the number of cycles for a particular stress level $\left(\omega_{i}\right)$, and $N_{i}$ is the number of allowable cycles for that stress level. The damage fraction for failure is normally unity (1.0). For the equivalent damage of one million cycles, Eq. A.1 becomes:

$$
\frac{n_{1}}{N_{1}}+\frac{n_{2}}{N_{2}}+\cdots+\frac{n_{n}}{N_{n}}=\frac{1 \times 10^{6}}{N_{e q}}
$$

The number of allowable cycles, $N$, is:

$$
N=\left(\frac{\sigma_{a}}{\sigma_{u}}\right)^{-m}
$$

where $\sigma_{a}$ is the applied stress, $\sigma_{u}$ is the ultimate stress, and $m$ is the inverse of the Wöhler (or $S-N)$ curve. The DEL analysis assumes a linear relation between stress and load (or moment in this case). Equation A.4 then becomes:

$$
N=\left(\frac{M_{a}}{M_{u}}\right)^{-m}
$$

where $M_{a}$ is the applied moment and $M_{u}$ is the ultimate moment. Equation A.4 is substituted into Eq. A.2 to obtain:

$$
\frac{n_{1}}{\left(\frac{M_{a 1}}{M_{u}}\right)^{-m}}+\frac{n_{2}}{\left(\frac{M_{a 2}}{M_{u}}\right)^{-m}}+\cdots+\frac{n_{n}}{\left(\frac{M_{a n}}{M_{u}}\right)^{-m}}=\frac{1 \times 10^{6}}{\left(\frac{M_{e q}}{M_{u}}\right)^{-m}}
$$

where $M_{e q}$ is the damage equivalent moment for one million cycles. Solving for $M_{e q}$ :

$$
M_{e q}=\left(\frac{\sum\left(M_{a i}\right)^{m} n_{i}}{1 \times 10^{6}}\right)^{1 / m}
$$


327

The rainflow cycle counting algorithm in NREL's Crunch program [22] was used to determined the number of cycles per simulation run for 30 moment levels. A separate Excel program was written to compute the DEL from the rainflow counts. The program adds up the cycles for the five 10-minute runs at each average wind speed step. It then multiplies these counts by $6 / 5$ and by the annual number of hours for the wind speed to get the total number of annual cycles in each moment level.

\section{Appendix B. 1.5 MW and 3 MW Blade Properties}

Table B.4: WP1500 blade properties

\begin{tabular}{|c|c|c|c|c|c|c|}
\hline Station & $\begin{array}{c}\text { Blade } \\
\text { Fraction }\end{array}$ & $\begin{array}{c}\text { Twist } \\
(\mathbf{d e g})\end{array}$ & $\begin{array}{c}\text { Chord } \\
(\mathbf{m})\end{array}$ & $\begin{array}{c}\text { Pitch } \\
\text { Axis } \\
\text { Ratio }\end{array}$ & $\begin{array}{c}\text { Aero } \\
\text { Center }\end{array}$ & $\begin{array}{c}\text { Mass } \\
(\mathrm{kg} / \mathbf{m})\end{array}$ \\
\hline 1 & 0.0000 & 11.1 & 1.925 & 0.500 & 0.50 & 1447.61 \\
\hline 2 & 0.0211 & 11.1 & 1.890 & 0.500 & 0.50 & 173.89 \\
\hline 3 & 0.2105 & 11.1 & 2.800 & 0.340 & 0.25 & 204.04 \\
\hline 4 & 0.4737 & 3.1 & 2.147 & 0.310 & 0.25 & 157.61 \\
\hline 5 & 0.7368 & 0.6 & 1.494 & 0.280 & 0.25 & 72.66 \\
\hline 6 & 1.0000 & 0 & 0.906 & 0.250 & 0.25 & 11.35 \\
\hline
\end{tabular}




\begin{tabular}{|c|c|c|c|c|c|}
\hline Station & $\begin{array}{l}\text { Flatwise } \\
\text { Stiffness } \\
\left(\mathbf{N} \cdot \mathbf{m}^{2}\right)\end{array}$ & $\begin{array}{l}\text { Edgewise } \\
\text { Stiffness } \\
\left(\mathbf{N} \cdot \mathbf{m}^{2}\right)\end{array}$ & $\begin{array}{l}\text { Torsional } \\
\text { Stiffness } \\
\left(\mathbf{N} \cdot \mathbf{m}^{2}\right)\end{array}$ & $\begin{array}{c}\text { AE } \\
\text { Product } \\
(\mathrm{N})\end{array}$ & $\begin{array}{c}\text { Airfoil } \\
\text { Filename }\end{array}$ \\
\hline 1 & $7.6815 \mathrm{E}+09$ & $7.6815 \mathrm{E}+09$ & $2.6552 \mathrm{E}+09$ & $1.7153 \mathrm{E}+10$ & cylinder \\
\hline 2 & $1.1281 \mathrm{E}+09$ & $1.1281 \mathrm{E}+09$ & $3.9418 \mathrm{E}+08$ & $2.5464 \mathrm{E}+09$ & cylinder \\
\hline 3 & $3.0477 \mathrm{E}+08$ & $6.4782 \mathrm{E}+08$ & $1.9215 \mathrm{E}+07$ & $2.7043 \mathrm{E}+09$ & s818_2703.dat \\
\hline 4 & $8.5919 \mathrm{E}+07$ & $2.7108 \mathrm{E}+08$ & $8.4613 \mathrm{E}+06$ & $2.0742 \mathrm{E}+09$ & s818_2703.dat \\
\hline 5 & $1.3668 \mathrm{E}+07$ & $7.0329 \mathrm{E}+07$ & $1.6868 \mathrm{E}+06$ & $9.2581 \mathrm{E}+08$ & s825_2103.dat \\
\hline 6 & $2.3129 \mathrm{E}+05$ & $7.8741 \mathrm{E}+06$ & $1.7943 \mathrm{E}+05$ & $1.1847 \mathrm{E}+08$ & s826_1603.dat \\
\hline
\end{tabular}

Table B.5: WP3000 blade properties

\begin{tabular}{|c|c|c|c|c|c|c|}
\hline Station & $\begin{array}{c}\text { Blade } \\
\text { Fraction }\end{array}$ & $\begin{array}{c}\text { Twist } \\
(\mathbf{d e g})\end{array}$ & $\begin{array}{c}\text { Chord } \\
(\mathbf{m})\end{array}$ & $\begin{array}{c}\text { Pitch } \\
\text { Axis } \\
\text { Ratio }\end{array}$ & $\begin{array}{c}\text { Aero } \\
\text { Center }\end{array}$ & $\begin{array}{c}\text { Mass } \\
(\mathbf{k g} / \mathbf{m})\end{array}$ \\
\hline 1 & 0.0000 & 11.1 & 2.673 & 0.500 & 0.50 & 2514.27 \\
\hline 2 & 0.0211 & 11.1 & 2.673 & 0.500 & 0.50 & 342.34 \\
\hline 3 & 0.2105 & 11.1 & 3.960 & 0.340 & 0.25 & 373.58 \\
\hline 4 & 0.4737 & 3.1 & 3.036 & 0.310 & 0.25 & 302.91 \\
\hline 5 & 0.7368 & 0.6 & 2.113 & 0.280 & 0.25 & 136.39 \\
\hline 6 & 1.0000 & 0 & 1.281 & 0.250 & 0.25 & 16.68 \\
\hline
\end{tabular}




\begin{tabular}{|c|c|c|c|c|c|}
\hline Station & $\begin{array}{c}\text { Flatwise } \\
\text { Stiffness } \\
\left(\mathbf{N} \cdot \mathbf{m}^{\mathbf{2}}\right)\end{array}$ & $\begin{array}{c}\text { Edgewise } \\
\text { Stiffness } \\
\left(\mathbf{N} \cdot \mathbf{m}^{2}\right)\end{array}$ & $\begin{array}{l}\text { Torsional } \\
\text { Stiffness } \\
\left(\mathbf{N} \cdot \mathbf{m}^{2}\right)\end{array}$ & $\begin{array}{c}\text { AE } \\
\text { Product } \\
(\mathrm{N})\end{array}$ & $\begin{array}{c}\text { Airfoil } \\
\text { Filename }\end{array}$ \\
\hline 1 & $2.5916 \mathrm{E}+10$ & $2.5916 \mathrm{E}+10$ & $8.9665 \mathrm{E}+09$ & $2.8944 \mathrm{E}+10$ & cylinder \\
\hline 2 & $4.5189 \mathrm{E}+09$ & $4.5189 \mathrm{E}+09$ & $1.5791 \mathrm{E}+09$ & $5.0974 \mathrm{E}+09$ & cylinder \\
\hline 3 & $1.3320 \mathrm{E}+09$ & $3.4791 \mathrm{E}+09$ & $6.2408 \mathrm{E}+07$ & $4.9586 \mathrm{E}+09$ & s818_2703.dat \\
\hline 4 & $3.4479 \mathrm{E}+08$ & $9.6503 \mathrm{E}+08$ & $2.5625 \mathrm{E}+07$ & $4.0027 \mathrm{E}+09$ & s818_2703.dat \\
\hline 5 & $5.4736 \mathrm{E}+07$ & $2.4072 \mathrm{E}+08$ & $5.1116 \mathrm{E}+06$ & $1.7456 \mathrm{E}+09$ & s825_2103.dat \\
\hline 6 & $6.9195 \mathrm{E}+05$ & $2.3690 \mathrm{E}+07$ & $5.4377 \mathrm{E}+05$ & $1.7586 \mathrm{E}+08$ & s826_1603.dat \\
\hline
\end{tabular}


[1] E. Bossanyi, B. Savini, M. Iribas, M. Hau, B. Fischer, D. Schlipf, T. van Engelen, M. Rossetti, C. E. Carcangiu, Advanced controller research for multi-MW wind turbines in the UPWIND project, Wind Energy 15 (2012) 119-145.

[2] S. J. Johnson, C. P. van Dam, D. E. Berg, Active load control techniques for wind turbines, SAND2008-4809, Sandia National Laboratories (August 2008).

[3] S. J. Johnson, J. P. Baker, C. P. van Dam, D. E. Berg, An overview of active load control techniques for wind turbines with an emphasis on microtabs, Wind Energy 13 (2010) 239253.

[4] D. W. Lobitz, P. Veers, R. Eisler, D. J. Laino, P. G. Migliore, G. Bir, The use of twist-coupled blades to enhance the performance of horizontal axis wind turbines, SAND2001-1303, Sandia National Laboratories (May 2001).

[5] B. S. Liebst, Wind turbine gust load alleviation utilizing curved blades, Journal of Propulsion 2 (4) (1986) 371-377.

[6] M. Zuteck, Adaptive blade concept assessment: Curved planform induced twist investigation, SAND2002-2996, Sandia National Laboratories (October 2002).

[7] Knight and Carver Wind Group, Sweep-twist adaptive rotor blade: Final project report, SAND2009-8037, Sandia National Laboratories (2010). 
[8] D. R. S. Verelst, T. J. Larsen, Load consequences when sweeping blades a case study of a 5 MW pitch controlled wind turbine, Ris $\varnothing-\mathrm{R}-1724(\mathrm{EN})$, RISØ and the Danish Technical University (2010).

[9] S. Larwood, Dynamic analysis tool development for advanced geometry wind turbine blades, Ph.D. thesis, University of California at Davis (2009).

[10] J. M. Jonkman, NWTC design codes (FAST), Available at: http://wind.nrel.gov/designcodes/simulators/FAST/ (Last update 5 July 2005).

[11] S. Larwood, C. P. van Dam, Dynamic analysis tool development for swept wind turbine blades, Wind Energy 16 (6) (2013) 879-907.

[12] Anonymous, Wind turbines - part 1: Design requirements, IEC 61400-1 Ed. 3, International Electrotechnical Commission (2005).

[13] N. D. Kelley, B. J. Jonkman, NWTC Computer-Aided Engineering Tools (TurbSim by Neil Kelley, Bonnie Jonkman) (30-May 2013).

[14] G. Freebury, W. Musial, Determining equivalent damage loading for full-scale wind turbine blade fatigue tests, in: 38th AIAA Aerospace Sciences Meeting and Exhibit, American Institute of Aeronautics and Astronautics, Reno, Nevada, 2000.

[15] H. J. Sutherland, On the fatigue analysis of wind turbines, SAND990089, Sandia National Laboratories (June 1999). 
[16] D. A. Griffin, WindPACT Turbine Design Scaling Studies Technical Area 1.Composite Blades for 80- to 120-Meter Rotor, NREL/SR-50029492, National Renewable Energy Laboratory (April 2001).

[17] J. M. Jonkman, C. P. Butterfield, W. D. Musial, G. N. Scott, Definition of a 5-MW Reference Turbine for Offshore System Development, NREL/TP-500-38060, National Renewable Energy Laboratory (February 2009).

[18] R. Gasch, J. Twele, Wind Power Plants, Solarpraxis, Berlin, 2002.

[19] M. L. Buhl Jr, NWTC Design Codes (WT_Perf), Available at: http://wind.nrel.gov/designcodes/simulators/wtperf/ (26 May 2005).

[20] M. H. Hansen, Aeroelastic Instability Problems for Wind Turbines, Wind Energy 10 (2007) 551577.

[21] D. W. Lobitz, Ramifications of aeroelastic analysis approximations as blade designs approach stability boundaries, in: 2004 ASME Wind Energy Symposium, American Society of Mechanical Engineers, Reno, NV, 2004, pp. 203-210.

[22] M. L. Buhl Jr, NWTC Design Codes (Crunch) (01 April 2008). 